\title{
Ribosomal DNA status inferred from DNA cloud assays and mass spectrometry identification of agarose-squeezed proteins interacting with chromatin (ASPIC-MS)
}

\author{
Kamil Krol ${ }^{1}$, Justyna Jendrysek ${ }^{1}$, Janusz Debski², Marek Skoneczny ${ }^{3}$, Anna \\ Kurlandzka³, Joanna Kaminska ${ }^{3}$, Michal Dadlez ${ }^{2}$, Adrianna Skoneczna ${ }^{1}$ \\ ${ }^{1}$ Institute of Biochemistry and Biophysics, Polish Academy of Sciences, Laboratory of Mutagenesis and DNA Repair, Warsaw, \\ 02-106, Poland \\ ${ }^{2}$ Institute of Biochemistry and Biophysics, Polish Academy of Sciences, Mass Spectrometry Laboratory, Warsaw, 02-106, \\ Poland \\ ${ }^{3}$ Institute of Biochemistry and Biophysics, Polish Academy of Sciences, Department of Genetics, Warsaw, 02-106, Poland \\ Correspondence to: Adrianna Skoneczna, email: ada@ibb.waw.pl
}

Keywords: nucleolus, genome instability, DNA structures, DNA-binding protein, Las 17

Received: May 16, $2016 \quad$ Accepted: January 23, $2017 \quad$ Published: February 15, 2017

Copyright: Krol et al. This is an open access article distributed under the terms of the Creative Commons Attribution License (CC-BY), which permits unrestricted use, distribution, and reproduction in any medium, provided the original author and source are credited

\section{ABSTRACT}

\begin{abstract}
Ribosomal RNA-encoding genes (rDNA) are the most abundant genes in eukaryotic genomes. To meet the high demand for rRNA, rDNA genes are present in multiple tandem repeats clustered on a single or several chromosomes and are vastly transcribed. To facilitate intensive transcription and prevent rDNA destabilization, the rDNA-encoding portion of the chromosome is confined in the nucleolus. However, the rDNA region is susceptible to recombination and DNA damage, accumulating mutations, rearrangements and atypical DNA structures. Various sophisticated techniques have been applied to detect these abnormalities. Here, we present a simple method for the evaluation of the activity and integrity of an rDNA region called a "DNA cloud assay". We verified the efficacy of this method using yeast mutants lacking genes important for nucleolus function and maintenance (RAD52, SGS1, RRM3, PIF1, FOB1 and RPA12). The DNA cloud assay permits the evaluation of nucleolus status and is compatible with downstream analyses, such as the chromosome comet assay to identify DNA structures present in the cloud and mass spectrometry of agarose squeezed proteins (ASPIC-MS) to detect nucleolar DNA-bound proteins, including Las17, the homolog of human Wiskott-Aldrich Syndrome Protein (WASP).
\end{abstract}

\section{INTRODUCTION}

For proper functioning, cells need high amounts of rRNA. In contrast to proteins, which can be produced in higher amounts by increasing mRNA levels, rRNA is the final gene product and cannot be amplified in subsequent expression steps. Thus, obtaining high amounts of rRNA gene products requires different mechanisms. In eukaryotic genomes, rDNA is present in multiple copies, tandemly repeated in a special chromosomal region. In Saccharomyces cerevisiae, 100-200 tandem repeats of $9.1 \mathrm{~kb}$ each are located on chromosome XII [1,2]. These repeats occupy approximately $60 \%(1.5 \mathrm{Mb})$ of the chromosome and constitute more than $10 \%$ of the total yeast genome [3]. The rDNA region is transcribed by RNA polymerase I to produce 35S rRNA [4] and RNA polymerase III to produce 5S rRNA [5]. In exponentially growing yeast, $60 \%$ of total transcription is devoted to rRNA [6], even though only one half of the rRNA genes present in the genome are transcriptionally active [7]. Highly expressed genome regions are more susceptible to DNA damage, and rDNA is no exception [8].

The repair of damage in rDNA regions is challenging. The repair pathways must adjust to the very active transcription of the region and the highly repetitive DNA sequences. The repair pathway recruited to DNA damage within rDNA sequences depends on the type of damage and expression level of the rDNA repeat. For 
example, UV-induced cyclobutane-pyrimidine dimers are repaired faster in active than in silenced genes by both photolyase and nucleotide excision repair, suggesting RNA polymerase I-dependent transcription-coupled repair [9]. Disturbances of massive transcription by a stressor or lack of certain RNA-processing factors frequently lead to the formation of co-transcriptional RNA:DNA hybrid structures (R-loops). R-loops often lead to double-stranded breaks (DSBs) but also have the potential to initiate originindependent, illegitimate replication [10-12]. R-loops drive subsequent genome instability due to DSB-provoked recombination or transcription-driven endoreplication.

Because of the repetitive nature of rDNA, the chromosomal region is highly recombinogenic, and the homologous recombination (HR) pathway is crucial for accurate maintenance of the region. The rDNA tandem repeats play a dual, contradictory role in this process. The repeats serve as template sequences during HR repair. However, their profusion may mislead HR when choosing a homologous sequence. The use of a distant rDNA unit as a repair template results in looping out of the DNA strand and, depending on the location of rDNA unit used, contraction events accompanied by extrachromosomal rDNA circle (ERC) formation or expansion events [1315]. As a result, the number of tandem repeats fluctuates, making the rDNA region the most unstable in the whole genome [16, 17]. Moreover, these shifts in rDNA repeat numbers appear to control whole-genome plasticity, which is responsible for adjusting cellular homeostasis in response to environmental changes $[18,19]$. To maintain both an accurate rDNA sequence and a proper rDNA copy number, various DNA repair pathways are employed $[9,20-22]$.

Pulsed-field gel electrophoresis (PFGE) is a standard technique in studies of genome-stability mechanisms. This technique enables separation of large DNA molecules such as yeast chromosomes, facilitating the identification of chromosome size abnormalities [23, 24] or the determination of the ability of a strain to repair DNA damage [25]. The interpretation of PFGE results is straightforward except when examining mutants that lack genes important for proper functioning of the nucleolus. In such mutants, the symptoms of instability in the rDNA region suggest changes in the rDNA copy number $[18,19,26]$. However, PFGE analysis of such strains also revealed an atypical DNA band migrating close to chromosome XII, which we refer to as "DNA clouds". We verified these observations using $S$. cerevisiae mutants lacking the RAD52, SGS1, RRM3, $P I F 1, F O B 1$ and $R P A 12$ genes. In these strains, replication, repair or transcription at rDNA regions is altered, resulting in the accumulation of various non-canonical DNA forms in the nucleolus. We adapted the chromosome comet assay, a method for visualizing atypical DNA structures, to analyze these non-canonical DNA forms [27]. To characterize DNA clouds in greater detail, we developed a novel technique involving the use of mass spectrometry to identify agarosesqueezed proteins interacting with chromatin (ASPIC-MS).
Here, we demonstrate that DNA clouds are in fact an altered form of chromosome XII that contains atypical DNA structures resulting from DNA damage, ongoing replication or transcription or as repair intermediates. Moreover, the DNA clouds contain various DNA-bound proteins important for nucleolar function. ASPIC-MS analysis identified Las 17 as a nucleolar protein engaged in nucleolar function, most likely nucleolar division, and ensuring nucleolar integrity. Because Las 17 is a homolog of the human WASP gene, whose mutation causes the human immunodeficiency Wiskott-Aldrich Syndrome, this finding might aid in elucidating the etiology of this disease.

\section{RESULTS}

\section{DNA cloud identification}

While studying yeast chromosome integrity by PFGE analysis, we observed, in addition to the normal electrophoretic patterns, dispersed bands we referred to as the "DNA cloud". We linked these signals with the ploidy of cells, with mutations in particular genes, and with some growth conditions (Figure 1). The separation patterns of identical DNA samples also differed depending on the conditions of electrophoresis (Figure 1A). We assumed that the DNA cloud might be derived from yeast chromosome XII because it migrated predominantly next to this chromosome. Because repetitive sequences are susceptible to disturbances in length and chromosome XII contains rDNA arrays, we assumed that the loss of rDNA units might destabilize chromosome XII. Thus, the DNA cloud located below chromosome XII might be a shortened chromosome $\mathrm{XII}$ or rDNA array excised from this chromosome.

However, in subsequent experiments, we established that the DNA cloud constituted the entire chromosome XII. Initially, we introduced a plasmid bearing the GAL1p promoter-regulated gene encoding I-PpoI homing endonuclease, which recognizes and cuts the sequence at the RDN25-1 gene located within every rDNA unit [28], to the BY4743 reference strain. I-PpoI endonuclease was overexpressed upon growth using galactose as a carbon source, and the chromosomal DNAs isolated from this strain and from the control untransformed BY4743 were subjected to PFGE. In the I-PpoI endonuclease-expressing strain, the DNA cloud was absent, which indicated that the DNA cloud contains rDNA (Figure 1B).

We subsequently analyzed PFGE patterns of BY4743 chromosomes subjected to restriction enzyme digestion analysis with various enzymes. We digested genomic DNA embedded in agarose using two different enzymes, BamHI and PmeI, which have numerous sites in the genome but not within the rDNA region; with I-PpoI, which cuts DNA solely within the rDNA unit; and with RecBCD nuclease, which digests linear but not circular DNA. As shown in Figure 1C and Figure 1D, the DNA cloud is present in the control sample but disappears or is strongly reduced in samples digested with enzymes. 


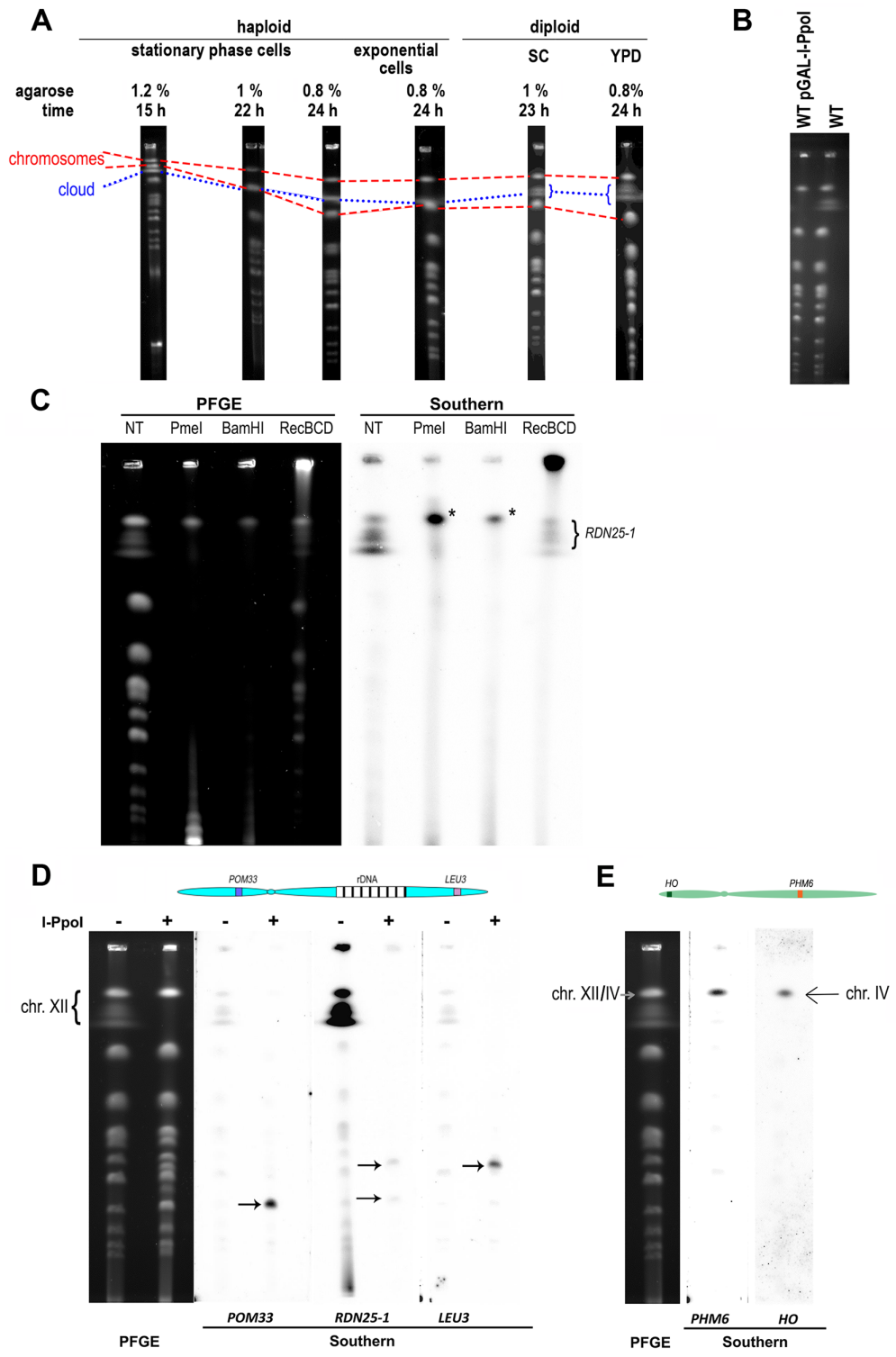

Figure 1: Characteristics of the DNA cloud. A. PFGE patterns differed when the same sample was separated under different electrophoretic conditions. Changes in the agarose concentration (we used $0.8 \%, 1 \%$, and $1.2 \%$ agarose) and/or duration of PFGE (15 hour, 22 hour and 24 hour separation times were applied) and changes in the yeast culture cultivation condition (exponentially grown cells treated with $15 \mu \mathrm{g} / \mathrm{ml}$ nocodazole and stationary-phase cells were employed) affected the DNA cloud positions in the gel. Differences in the shapes of the DNA cloud between haploid (BY4741) and diploid (BY4743) yeast were also observed. The dotted line shows the location of the DNA cloud on the PFGE gel, whereas the dashed lines show the locations of the chromosomal bands: the upper line reflects the location of chromosomes XII/IV, and the lower line reflects the location of chromosomes XV/VII on the gel. B. WT (BY4743) strain with and without the plasmid pGAL-I-PpoI were grown to exponential phase $\left(1 \times 10^{7}\right.$ cells per ml) on SC-URA or SC medium supplemented with $2 \%$ galactose as a carbon source, respectively. Then, the cells were synchronized in G2/M phase with nocodazole (15 $\mu \mathrm{g} / \mathrm{ml}, 3 \mathrm{hours})$, and PFGE was performed (0.8\% agarose, 24 hour separation time). C. The PFGE-separated DNA from the WT (BY4743) strain was digested with the indicated enzymes. The left image shows the EtBr-stained gel, and the right image shows the Southern blot of the same gel, probed with RDN25-1. The asterisk indicates the rDNA array. D. The PFGE-separated DNA from the WT (BY4743) strain non-treated and digested with I-PpoI. After PFGE separation, DNA was blotted onto nylon membranes and hybridized with three different probes. The left image shows the EtBr-stained gel, and the right image shows the Southern blot of the gel, probed with POM33, RDN25-1 and LEU3. The hybridization signals correspond to chromosome XII. Arrows show the position of the chromosome XII arms released after excision of the rDNA array. On the top, a drawing of chromosome XII marking the approximate locations of the genes used as probes. Picture not to scale. E. The PFGE-separated DNA from the WT (BY4743) strain. After PFGE separation, the DNA was blotted onto nylon membranes and hybridized with two different probes specific to chromosome IV. The left image shows the EtBr-stained gel, and the right image shows the Southern blot of the same gel, probed with $\mathrm{HO}$ and PHM6. On the top, a drawing of chromosome IV marking the approximate locations of the genes used as probes. Picture not to scale. 
Southern blot analysis of the same PFGE-separated DNAs with a fragment of RDN25-1 as the probe revealed more details. In the sample digested with I-PpoI, two signals, indicated by arrows, were present. These signals most likely corresponded to arms of chromosome XII released after excision of the rDNA region and were also visible on the EtBr-stained gel. To verify this fact, we analyzed the DNA released from the WT strain and separated by PFGE using Southern hybridization with three different probes: the RDN25-1 gene fragment to detect rDNA, as well as fragments of the POM33 and $L E U 3$ genes located close to the termini of the left arm and the right arm of chromosome XII, respectively. All three probes hybridized to the chromosome XII band and to the DNA cloud, indicating that the DNA cloud contains a significant part or even the whole of chromosome XII (see Figure 1D). When DNA in the plug was digested with I-PpoI, the probes recognized the corresponding remnants of chromosome XII. The POM33 probe hybridized with the left fragment of chromosome XII (lower band, approximately $0.45 \mathrm{Mbp}$ ), the $L E U 3$ probe hybridized with the right fragment of chromosome XII (upper band, approximately 0.61 Mbp), and the RDN25-1 probe recognized both chromosome XII fragments (Figure 1D).

Both, BamHI and PmeI digestions of genomic DNA embedded in agarose caused fragmentation of the yeast genome, except for the region containing the rDNA repeats. These rDNA-array-containing fragments migrated on PFGE gels as a single band (marked on Figure 1C with an asterisk) and hybridized with the RDN25-1 probe the Southern blots. Since the location of the rDNA-array-containing fragment is similar to that of the whole chromosome XII band, and because the difference between these two molecules is at least $0.91 \mathrm{Mbp}$ (the DNA length corresponding to 100 rDNA unit repeats), we asked where chromosome IV (1.53 Mbp) migrates on the PFGE gel. Using two different probes, namely, a fragment of the $\mathrm{HO}$ gene located on the left arm of chromosome IV and a fragment of the PHM6 gene located on the right arm of the same chromosome, we showed that chromosome IV migrated together with chromosome XII under the applied electrophoresis conditions (see Figure 1E).

In the sample of genomic DNA embedded in agarose digested with RecBCD, the bulk of the signal was visible in the proximity of the loading well. This signal most likely reflects extrachromosomal rDNA circles (ERCs). We verified this assumption using a chromosome comet assay approach [27]. Indeed, the DNA stuck in the well of the RecBCD-treated sample contained DNA circles of different sizes, but mostly large circles, circles linked to linear DNA (which we termed balloon-type structures) and very large branched structures, whereas untreated samples contained mostly branched DNA and much less frequent DNA circles, mainly of small and medium sizes (see Supplementary Figure 1).
When analyzing chromosomal patterns obtained after PFGE, we also observed that the shapes of the DNA clouds differed depending on the enzymes used for DNA digestion (Figure 1C), and we assumed that these shape differences may correspond to differences in DNA structures present in the cloud. To verify this assumption, we used two approaches. First, we analyzed the DNA of mutant strains that lacked genes that promote the appearance of DNA non-canonical forms, such as $\mathrm{X}$ structures, R-loops, or circular structures. For this experiment, we used the rrm3/rrm 3 strain, in which the HR pathway is stimulated [20]; the pifl/pifl strain, in which R-loops are sustained [29]; and the $\mathrm{sgs} 1 / \mathrm{sgs} 1$ strain, in which ERC formation is stimulated [30]. Because the Rad52 protein is crucial for HR, we expected that, compared to the reference strain, DSBs would accumulate in rad52/rad52, but X-shaped structures and ERCs would be decreased. In this experiment, we also included a strain lacking the RPA12 gene encoding the subunit of RNA polymerase I [31] and a strain lacking the $F O B 1$ gene encoding the replication fork barrier binding protein, which is important for the recombination activity of the rDNA region [32].

PFGE separation of chromosomes unveiled different shapes of the chromosome XII cloud in all strains (see Figure 2A). Southern blot analysis of separated DNA also revealed differences in the hybridization signals that did not correspond to the amount of DNA in the gel visualized by EtBr staining. The DNA cloud was clearly divided into fractions in BY4743, but only some of these fractions were present in other strains. Notably, the uppermost band of this chromosome migrated on PFGE gel together with chromosome IV (Figure 1E) and with rDNA arrays excised from chromosome XII (Figure 1C), hereafter referred to as chromosome XII/IV. This merged migration of high-molecular-weight molecules on PFGE gels led to the differences between the EtBr-stained PFGE images and the Southern blots. Samples of rad52/rad52 and fob1/ fobl contained only the lower bands visible in the cloud

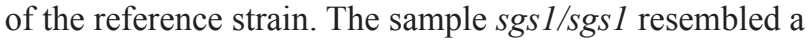
BamHI- or PmeI-digested sample of the control strain, as shown in Figure 1C, suggesting incisions and subsequent relaxation of DNA in this strain. Consequently, the rDNA sequences in the chromosome XII/IV band were more accessible for hybridization with the RDN25-1 probe. In the sample derived from pifl/pif1, the strengths of the hybridization signals from the DNA cloud and from chromosome XII/IV were comparable. The rrm3/rrm3derived sample hybridized very weakly, which suggested that for some reason, both chromosome XII/IV and the cloud may have been inaccessible to the probes. The band intensities of the rpa12/rpa12 sample were similar to those of WT; however, some bands in the DNA cloud were missing.

To demonstrate that migration of the DNA cloud in PFGE depends not only on the DNA length but also on 


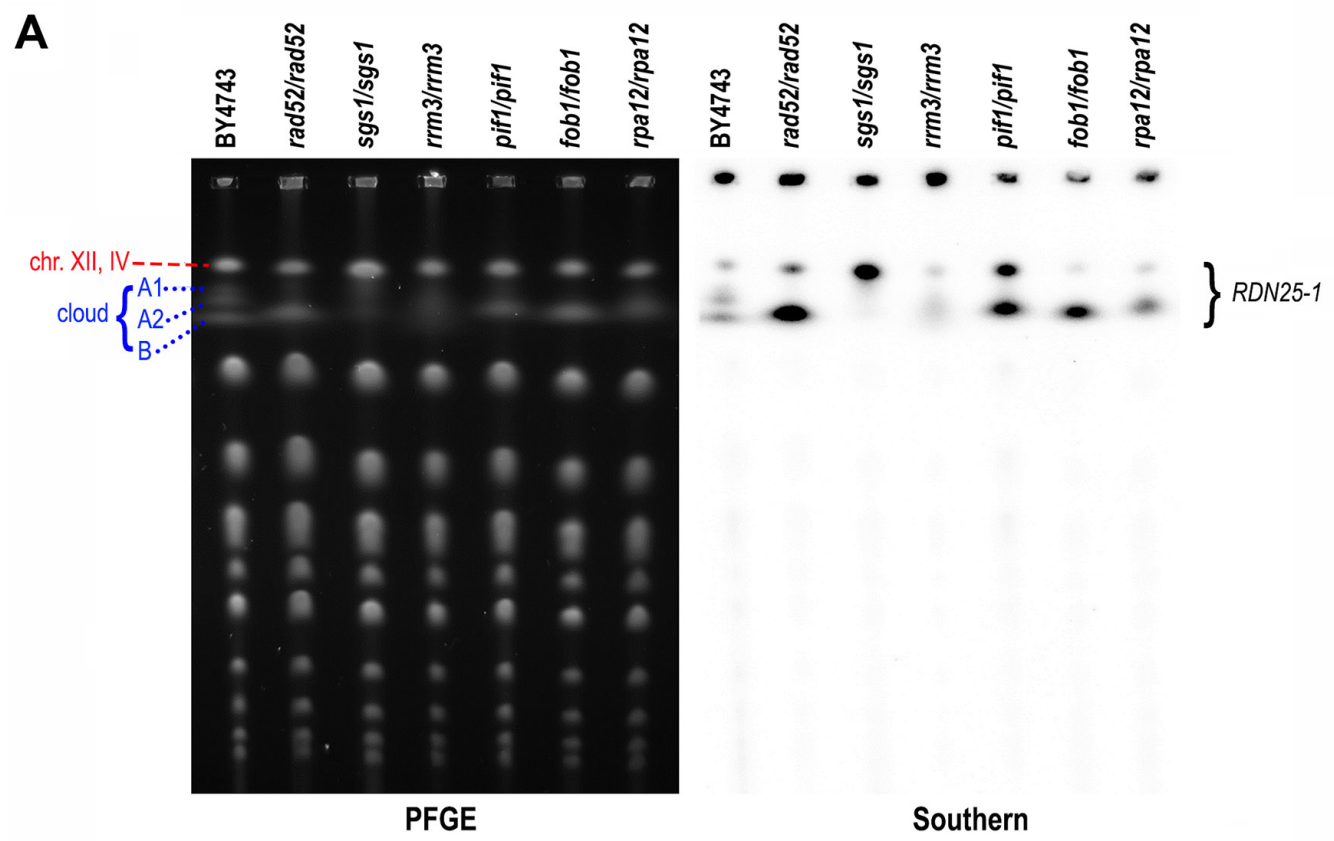

B

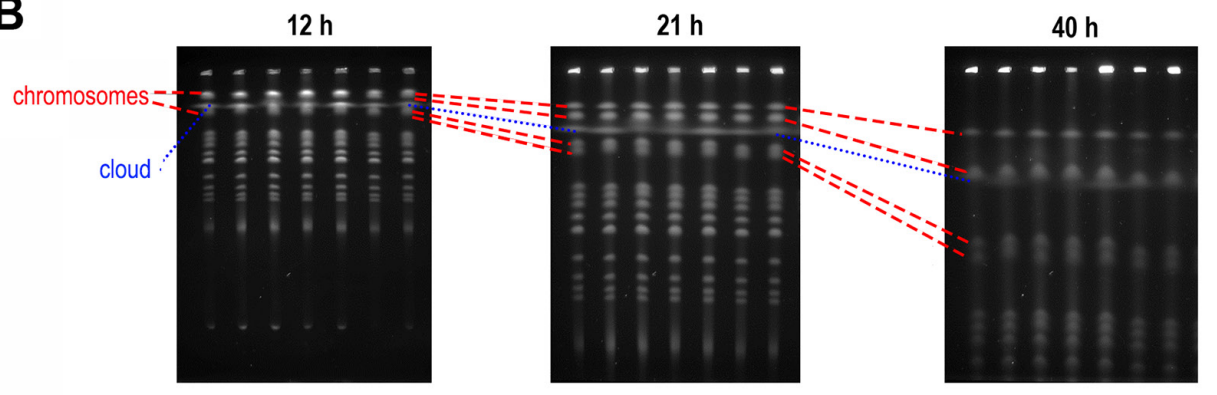

C

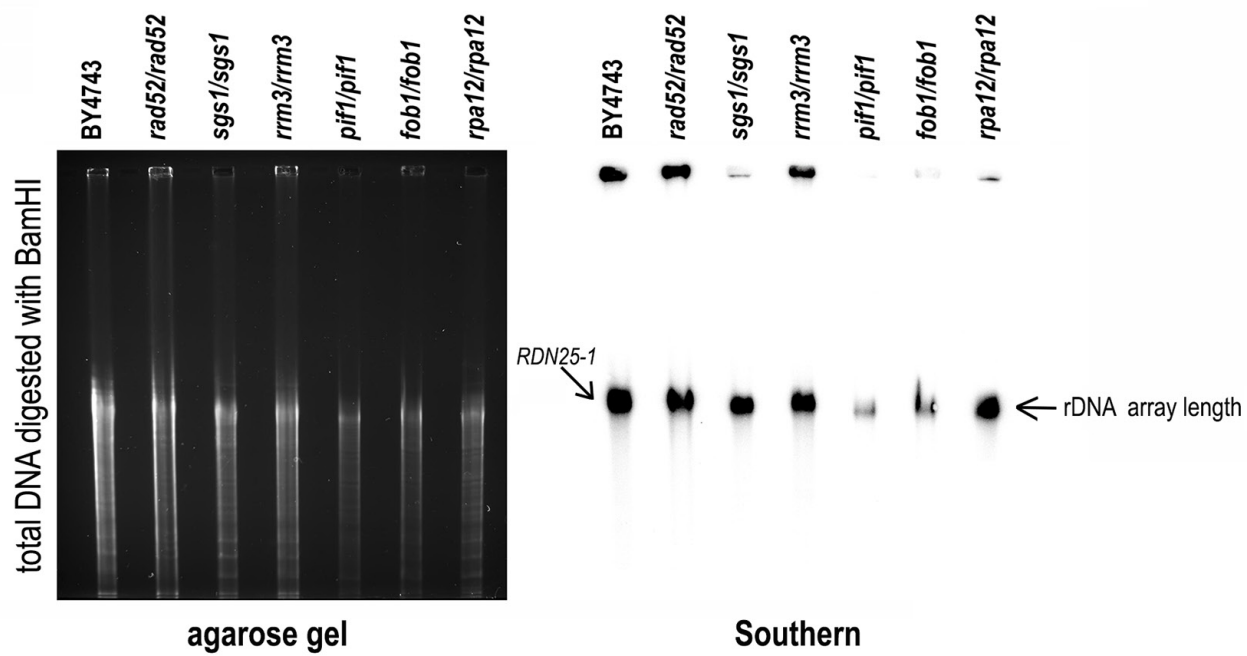

Figure 2: DNA cloud migration in PFGE depends on the length and shape of the DNA molecules in the cloud. A. The DNA cloud changed shape when transcriptional activity or repair in the rDNA region of chromosome XII was affected. PFGE analysis (left) and Southern blot analysis performed using [ $\left.\alpha^{32} \mathrm{P}\right]$ ATP-labeled $R D N 25-1$ probe (right) of chromosomal DNA of the BY4743 strain and its derivatives lacking RAD52, SGS1, RRM3, PIF1, FOB1 and RPA12 genes. B. The DNA cloud migrated at a different speed than the chromosomal bands. The chromosomal patterns obtained after 12 hours, 21 hours and 40 hours of DNA separation. The strains used in the experiment lacked the same genes as in (A) in the BY4741 background. The dotted line shows the location of the DNA cloud on the PFGE gel, whereas the dashed lines show the location of the respective chromosomal bands (from the top, chromosomes XII/IV, XV/VII, XVI and XIII). C. The analyzed strains contained a similar number of rDNA repeats. Southern blot analysis of BamHI-digested total DNA isolated from the same strains as in (A) after 15 hours of separation by PFGE in $1 \%$ agarose. Hybridization was performed with a $\left[\alpha^{32} \mathrm{P}\right]$ ATP-RDN25-1 probe. The analysis demonstrated that the strains contained a similar number of rDNA repeats. 
its spatial structure, we followed the cloud migration in a time-course experiment. We analyzed the chromosomal patterns of rad52, sgs1, rrm3, pif1, fob1 and rpal2 deletion mutants during a 40 hour-long PFGE. The results presented in Figure 2B show different locations of the DNA cloud relative to other chromosomes at different time points. After 12 hours of electrophoresis, the DNA cloud overlapped chromosomal bands (XIII/XVI), which then passed it during the subsequent 9 hours of electrophoresis. After 21 hours of electrophoresis, the DNA cloud was present between two chromosome sets, XV/VII and XIII/XVI. Finally, after 40 hours, the DNA cloud was in the proximity of chromosomal bands XV/VII. Since chromosomes XIII and XV differ in size by almost $100 \mathrm{~kb}$, DNA cloud migration is not linearly proportional to size.

To determine if migration of the DNA cloud in PFGE depends on the number of rDNA arrays in chromosome XII, we performed Southern blotting to analyze BamHI-digested total DNA isolated from various yeast strains. As mentioned above, BamHI does not cleave within rDNA, and thus the whole array should be excised from chromosome XII as one fragment. This experiment allowed us to compare the number of rDNA repeats present in the genome of the analyzed yeast strains. As shown in Figure $2 \mathrm{C}$, there were no differences in rDNA length between the control BY4743 strain and its derivatives $\mathrm{rad} 52 / \mathrm{rad} 52, \mathrm{sgs} 1 / \mathrm{sgs} 1, \mathrm{rrm} 3 / \mathrm{rrm} 3$, pif1/ pif1, fob1/fob1 and rpa12/rpa12. Therefore, the length of the rDNA region is not responsible for aberrant migration of the cloud.

\section{Detailed analysis of DNA cloud content}

Because DNA clouds adopt different shapes depending on growth conditions or mutations present in the genome, we assumed that the DNA structures within these clouds may vary. We also presumed that if proteins are responsible for the unusual migration of the DNA cloud in PFGE, these proteins should persist after proteinase $\mathrm{K}$ digestion during PFGE sample preparation and might be detectable after electrophoresis.

\section{Detection of various aberrant structures within the DNA cloud using a chromosome comet assay}

The chromosome comet assay is designed for the assessment of DNA structures [19, 27, 33, 34]. Using this technique, we analyzed both chromosome XII/ IV and the DNA cloud of strains lacking the RAD52, SGS1, RRM3, PIF1, FOB1, and RPA12 genes. We employed diploid strains homozygous for the deleted genes with the expectation that signals would be more pronounced than in haploid strains (see Figure 1A). Bands representing chromosome XII/IV and the cloud were excised from the PFGE gel and subjected to DNA electrophoresis under denaturing conditions. The DNA was then labeled with fluorescent dye and examined on a fluorescence microscope. Example images and the results of quantitative analysis are shown in Figure 3 (see Supplementary Figure 2 for more images).

The predominant DNA structures observed in rad52/rad52 were short fragments in the cloud and large circular DNA molecules in the XII/IV chromosomal band. Additionally, in these samples, broken DNA strands and Y structures were overrepresented. In the strain $s g s 1 / s g s 1$, we observed mostly linear DNA of different lengths, as well as $\mathrm{Y}$, branched and $\mathrm{X}$ structures. In fobl/fobl and rpa12/rpa12 samples, the most abundant category was linear DNA. However, the proportions of short and long strands in the DNA cloud and the chromosome XII/IV band in these samples varied. Whereas short DNA strands predominated in the cloud of fobl/fob1, in chromosome XII/IV of this sample, long DNA strands dominated in the cloud. In the rpa12/rpa12 strain, we observed the opposite; that is, the proportion of short DNA strands was higher in the chromosomal band, and long DNA strands were more frequent in the cloud. In $\mathrm{rrm} 3 / \mathrm{rrm} 3$, the long linear DNA, condensed chromosomes and Y structures were present in both chromosome XII/IV and the cloud samples. These samples differed in frequency compared to the circular forms and short DNA strands. Circular DNA was abundant in the chromosome XII/IV band, whereas short DNA fragments were more frequent in the cloud. In the mutant pif1/pif1 condensed chromosomes, long linear DNA and Y structures were much more abundant in the cloud, whereas the chromosome XII/IV band was dominated by circular DNA.

Chromosome XII/IV samples of the WT strain (BY4743) contained all described categories of DNA structures; however, the representation of various structures in specific fractions of the WT DNA cloud differed. The cloud fraction located nearest to chromosomal band (A1) was dominated by circular DNA forms and contained significant amount of DSBs that were visible in the comet assay as gaps in linear DNA structures. The middle fraction of the DNA cloud (A2) contained mostly long linear DNA but also the highest number of Y structures and lariats. The cloud fraction (B), the most distant from the chromosomal band, was dominated by short DNA fragments but contained branched DNA forms and $\mathrm{X}$ structures as well.

\section{ASPIC-MS: a method for detecting proteins tightly bound to DNA}

The chromosome comet assay revealed that, apart from other DNA forms, samples of chromosome XII/ IV contained condensed chromosomes (see Figure 3, Supplementary Figure 2). Thus, despite the significant amount of proteinase $\mathrm{K}$ used during preparation, the chromosomal samples apparently contained some proteins; otherwise, such condensed structures would not 
be preserved. Thus, we assumed that atypical structures detected in the comet assay might also contain some proteins bound to DNA. Identification of these proteins would enhance the characterization of the DNA cloud. To detect proteins recovered from agarose, we developed a novel, mass spectrometry-based method: ASPIC-MS. A detailed description of this method is provided in the Materials and Methods. We used this method to identify proteins present in the DNA cloud and chromosome XII/IV derived from mutant strains, and the results are summarized in Table 1 .

We assumed that the detected proteins were tightly bound to DNA, and the detected proteins appeared to be specific to the analyzed strain. In all strains except rad52/ rad52, we detected the protein Scc2. Remarkably, rad52/ rad52 and pif1/pif1 contained the Yku80 protein in both chromosome XII/IV and the DNA cloud. This protein was also detected in $\mathrm{sgs}_{1 / \mathrm{sgs} 1}$ and $\mathrm{rrm} 3 / \mathrm{rrm} 3$ chromosome XII/IV. The Tfb3 protein was present in the rad52/rad52 and sgs1/sgs 1 chromosome samples and in the rpa12/ rpa12 DNA cloud. The Sod1 protein was observed in chromosome XII/IV of WT and in the DNA clouds of $\mathrm{rad} 52 / \mathrm{rad} 52$ and $s g s 1 / \mathrm{sgs} 1$.
The protein Las 17 was present in the DNA cloud of the WT strain and in the rad52/rad52 and rpa12/rpal2 mutant strains. Because Las 17 is localized in actin cortical patches or in the cytoplasm [35], nucleolar localization of Las17 was rather unexpected. We verified this result by microscopic observations of the cellular localization of Las 17. We used GFP-tagged Las17 and the nucleolar marker Nop1-dsRed fusion protein. The pWJ1322 plasmid encoding the Nop1-DsRed gene [22] was introduced to the KAY757 strain carrying the Las17-GFP fusion in the genome [36]. We detected the Las17-GFP protein in the nucleolus of cells (see Figure 4A), co-localized with Nop1-DsRed. We also examined the morphology of the nucleolus in las $17 \Delta$ mutant cells. As shown in Figure 4B, Las 17 is necessary for the integrity and proper division of the nucleolus. This requirement was particularly apparent when we analyzed the morphology of the nucleolus in WT (RLY1) and las 174 (RLY157) cells after synchronization with nocodazole (see Supplementary Figure 3). Various abnormalities linked with timing, polarity of nucleolus division, cells containing multiple nucleoli, and different patterns of nucleolus fragmentation were observed in the las 174 mutant. Thus, ASPIC-MS is a powerful tool not

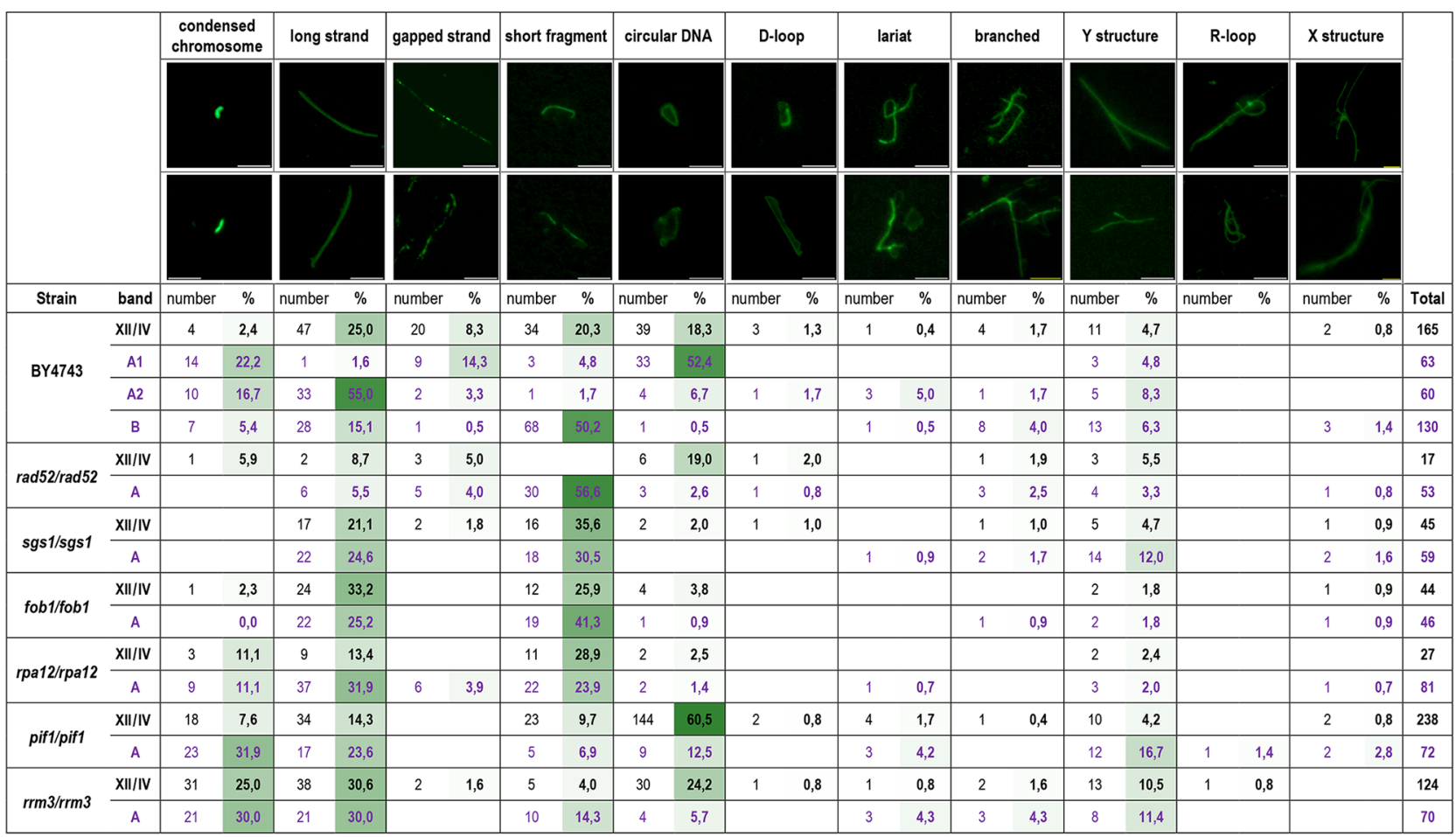

Figure 3: DNA structures present in chromosome XII and the DNA cloud revealed by the comet assay. Samples were derived from the WT (BY4743) strain and its derivatives lacking the RAD52, SGS1, RRM3, PIF1, FOB1 and RPA12 genes. Separate analyses of various fractions of the DNA cloud of reference strain BY4743 were performed. The A1 fraction was nearest to the chromosome XII band, A2 was in the middle, and B was the most distant from chromosome XII (see Figure 2A). Above the table, examples of certain DNA structures are shown (scale bar, $5 \mu \mathrm{m}$ ). The numbers of each type of DNA structure observed in the chromosome comet assay were counted. The percentages of these structures with respect to all structures detected with certain probes were also calculated. The intensity of green color represents the contributions of specific DNA structures in the respective samples; darker green indicates a more abundant DNA structure in the sample. 
Table 1: Proteins identified by ASPIC-MS in chromosome XII/IV and DNA cloud bands of the studied strains

\begin{tabular}{|c|c|c|c|c|c|c|c|c|c|c|c|c|c|c|c|}
\hline & \multicolumn{3}{|c|}{ BY4743 } & \multicolumn{2}{|c|}{$\mathrm{rad} 52 / \mathrm{rad} 52$} & \multicolumn{2}{|c|}{ sgs1/sgs1 } & \multicolumn{2}{|c|}{ fob1/fobl } & \multicolumn{2}{|c|}{ rpa12/rpa12 } & \multicolumn{2}{|c|}{ rrm3/rrm3 } & \multicolumn{2}{|c|}{ pif1/pif1 } \\
\hline & $\begin{array}{c}\text { XII/ } \\
\text { IV }\end{array}$ & $\mathbf{A}$ & B & $\begin{array}{c}\text { XII/ } \\
\text { IV }\end{array}$ & $\mathbf{A}$ & $\begin{array}{c}\text { XII/ } \\
\text { IV }\end{array}$ & $\mathbf{A}$ & $\begin{array}{c}\text { XII/ } \\
\text { IV }\end{array}$ & $\mathbf{A}$ & $\begin{array}{c}\text { XII/ } \\
\text { IV }\end{array}$ & $\mathbf{A}$ & $\begin{array}{c}\text { XII/ } \\
\text { IV }\end{array}$ & $\mathbf{A}$ & $\begin{array}{c}\text { XII/ } \\
\text { IV }\end{array}$ & $\mathbf{A}$ \\
\hline Las 17 & & + & & & + & & & & & & + & & & & \\
\hline $\operatorname{Scc} 2$ & & & + & & & + & + & + & + & + & & & & & \\
\hline Smc3 & & & & & & & & & & & & + & + & & + \\
\hline Sod1 & & + & & + & & + & & & & & & & & & \\
\hline Tfb3 & & & & + & & + & & & & & + & & & & \\
\hline Yku80 & & & & + & + & + & & & & & & + & & + & + \\
\hline
\end{tabular}

only for verifying the localization of proteins in atypical DNA structures but also for identifying proteins that have not been detected in the nucleolus previously.

\section{DISCUSSION}

While using the PFGE technique to study chromosomes of yeast mutants deficient in genome maintenance pathways, we observed that, depending on the separation conditions applied to DNA samples, the regular chromosome patterns displayed irregular bands that we denoted DNA clouds. Our observations of these atypical bands were not consistent explanations of this phenomenon available in literature. According to Kobayashi et al. [37], the association of the DNA cloud migration speed in the PFGE with rDNA array length is limited to yeast mutants that stimulate these types of changes, such as mre 11 or sir2. As expected, experiments employing artificial yeast with a manipulated number of tandem repeats in the genome demonstrated that the length of the rDNA region contributed to the position of chromosome XII in the PFGE pattern [18]. However, researchers from the same group observed unexpected differences in cloud migration between DNA samples obtained from the same mutant strain $[37,38]$ but could not identify a good explanation for this phenomenon [37]. Others have also observed the DNA cloud while studying the mobility of yeast chromosomes released from the double mutant strain slx4 sgs1-35 (ts) but believed that the altered mobility of chromosome XII occurred only when cells progressed through S-phase at restrictive temperatures [39]. Another explanation for the DNA cloud was proposed by Lewinska et al. [34], who assigned differently migrating DNA containing the rDNA region to multimeric ERCs. Although each author attributed the DNA cloud to different molecular events, all agreed that the DNA cloud contains rDNA. Based on our results (Figures 1,2), aberrant migration of the DNA cloud cannot be ascribed exclusively to changes in the number of tandem repeats in the rDNA array because strains containing a similar number of rDNA units on chromosome XII display different shapes and mobility of the DNA cloud after separation of chromosomes by PFGE. The DNA cloud migration speed appears to depend on the electrophoretic separation conditions, and variability is particularly evident when PFGE conditions favor the separation of large chromosomes.

The majority of researchers who have employed PFGE analysis of yeast chromosomes have not reported DNA clouds, possibly due to incomplete digestion of the cell wall of agarose-embedded cells. If digestion is incomplete, aberrant chromosomal structures might not be released from the plugs. This deduction is supported by the observation that DNA released from strains that accumulate $\mathrm{X}$ structures, such as the $\gamma$-irradiated rad50 strain, can be stacked in the wells of the gel [40]. Our experiment employing RecBCD treatment of DNA plugs (see Figure 1C) confirmed this observation. The RecBCD helicase/nuclease contributes to homologous recombination in bacteria [41] and likely possesses some recombinogenic potential in vitro, because DNA that is treated with this enzyme displays obvious structural changes. As shown in Figure $1 \mathrm{C}$, the migration of agarose-embedded DNA digested with RecBCD was strikingly different in PFGE: the RecBCD-treated DNA sample remained in the well and produced a strong signal detected by Southern blotting, which was absent in nontreated samples, indicating that RecBCD-treatment caused the sample to become "stuck" in the well. Comparisons by chromosome comet assay revealed clear differences between the structures of DNA in RecBCD-digested BY4743 samples stuck in the wells of PFGE gels and those of non-treated samples. These differences were not limited to the expected decrease in linear structures due to the exonuclease activity of the enzyme. Although control samples mainly contained branched DNA structures, as well as some linear and some circular DNA, the RecBCDdigested sample contained elevated amounts of large circular DNA, balloon-type structures and large branched DNA structures with different shapes compared with those in the control sample, which were clearly unable to leave the wells of the PFGE gel (see Supplementary 
A
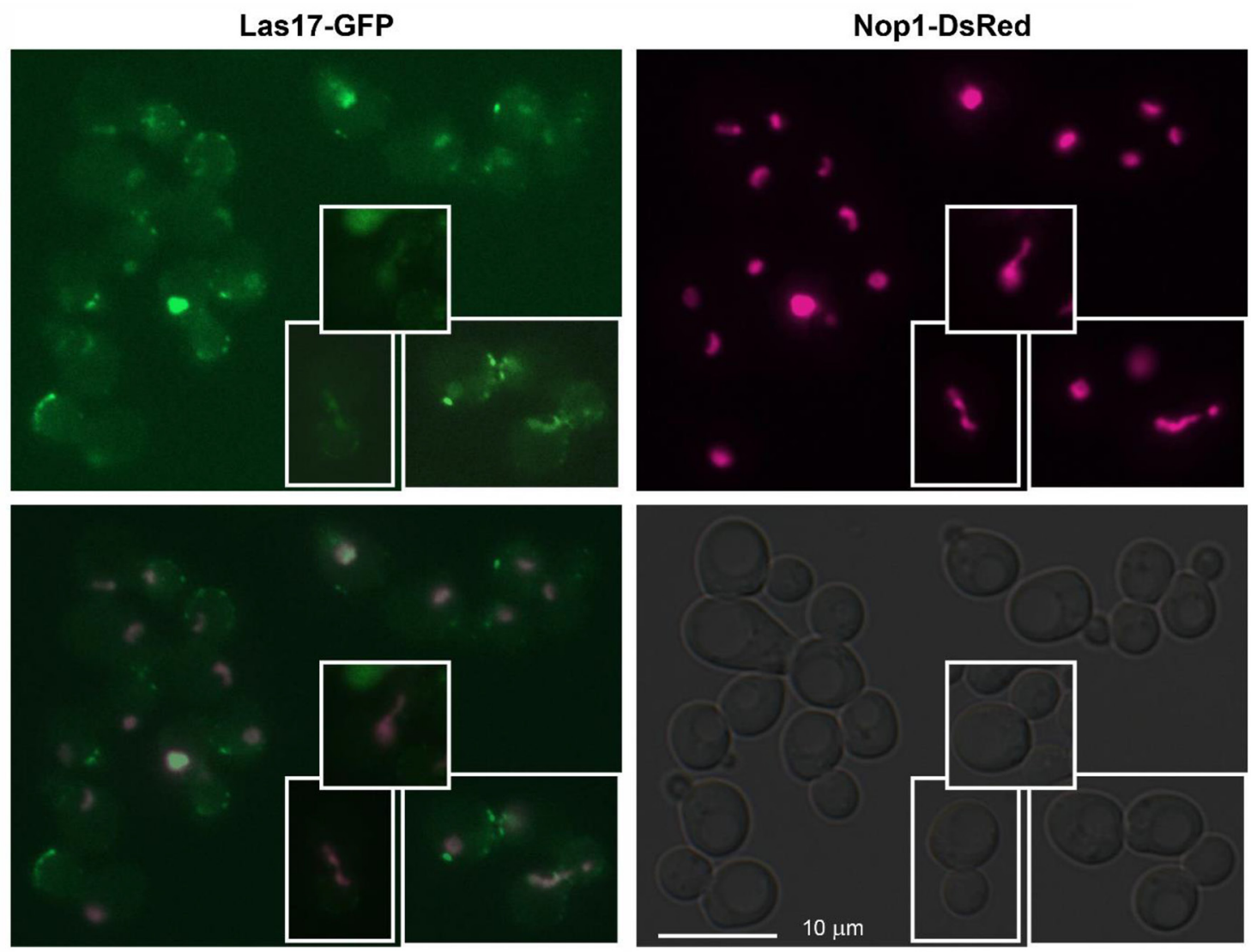

marge

DIC

B

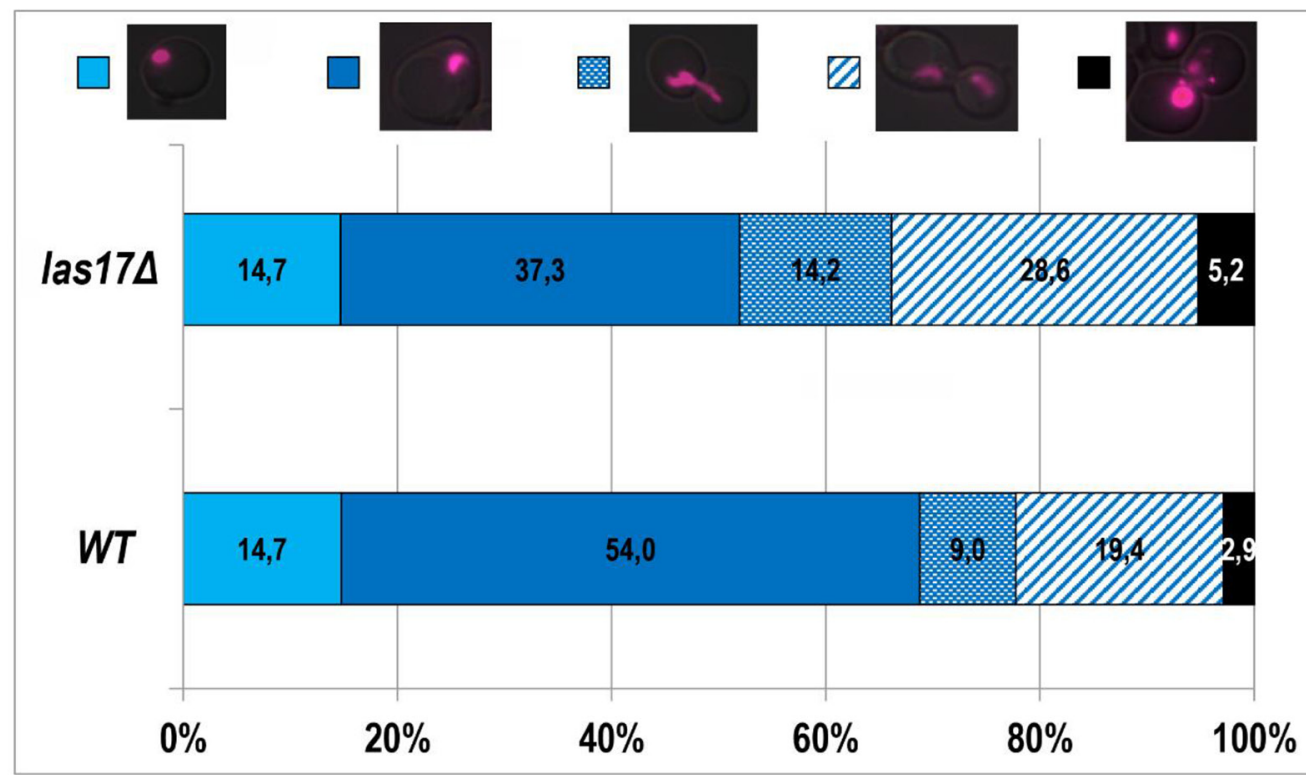

Figure 4: Nucleolar localization of Las17. A. Co-localization of Las17-GFP and Nop1-DsRed in the yeast nucleolus. The plasmid pWJ1322 bearing Nop1-DsRed (the nucleolus marker) was introduced into the KAY757 strain bearing LAS17-GFP. Exponentially growing cells were examined by fluorescence microscopy. Changes in the nucleolus shape were typical for the cells in different cell cycle phases. B. Nucleolus morphology in WT (RLY1) and las174 (RLY 197) cells. Cells transformed with pWJ1322 plasmid expressing Nop1-DsRed. The percentages of cells showing the respective phenotypes were counted from at least 350 cells. 
Figure 1). Aside from its 5'-3' and 3'-5' exonuclease activity, RecBCD also exhibits structure-selective binding to Y- type structures, DNA gaps, or DSBs [42, 43]. RecBCD can independently resolve X-type structures [44] and is involved in replication termination and DSB repair, including alternative end-joining $[45,43]$. Therefore, it is highly probable that yeast DNA might be processed by this enzyme, especially yeast DNA abounding with atypical DNA structures, such as rDNA arrays.

Using I-PpoI homing nuclease and Southern blot analysis, we demonstrated that the DNA cloud contains not only the rDNA region but also whole chromosome XII (Figure 1D). The results of digestion of agaroseembedded DNA with various enzymes as well as the changes in the cloud shape and mobility depending on the tested strain and employed separation conditions (Figures $1,2)$ suggested the presence of different DNA structures in the chromosome XII/IV band and cloud. The presence of different DNA structures implies that the DNA cloud migration rate is dependent not only on molecular mass but also on alterations of DNA structures.

Using a chromosome comet assay, we demonstrated that categories of DNA structures observed in the cloud, as well as their proportions, varied in different mutants. We observed that the shape of the cloud is characteristic for a certain mutant and is determined by the DNA spatial structures it contains. Moreover, the DNA structures observed in the mutants matched the expected patterns. In rad52/rad52, which is defective in HR, we observed a lack of $\mathrm{X}$ and circular structures. A functional HR pathway is necessary for the creation of these structures $[13,14]$. Because HR is the major pathway engaged in DSB repair, the rad52/rad52 strain accumulates DSBs, and we frequently observed short DNA fragments and gaps in the DNA (see Figure 3). The results of ASPIC-MS analysis were in agreement with these findings. In rad52/ rad52-derived samples, the Yku80 protein was detected, which suggests the mobilization of an alternative DSB repair pathway, i.e., the non-homologous end joining pathway, and recruitment of Yku80 protein to the damage sites [13, 46]. Samples of rad52/rad52 were also devoid of Scc2 protein, the subunit of the cohesion loading complex [47]. Of course, we do not want to overstate the quantitative nature of mass spectrometry; although MS can provide insights into the presence of certain proteins in a preparation, the absence of a signal does not entail the absence of a protein, especially when samples are extensively predigested with proteinase K. Nevertheless, this observation is consistent with a role of cohesion in DSB repair because Scc2 is crucial for loading the Smc1 subunit of the cohesion complex onto the DSB site [48]. The cohesion performs tethering of sister chromatids at extended chromosome regions surrounding DSB, where Rad52 is recruited, facilitating the repair of damage by HR [49]. Cohesion ensures equal recombination between sister chromatids and thus reduces the likelihood of deleterious recombination [50].
By contrast, samples derived from strains sgs $1 /$ sgs 1, fob1/fob1 and rpa12/rpa12 contained Scc2, as well as less short DNA fragments and more long DNA strands, indicating more efficient HR in these strains (see Table 1, Figure 3). In strains rrm3/rrm3 and pifl/pifl, even fewer DSBs and short DNA fragments were observed. These strains also contain $\mathrm{Smc} 3$ protein, the subunit of the cohesion complex. These data suggest that the position of the DNA cloud with respect to the chromosome XII/ IV band reflects the DNA strand length and its degree of condensation. The more distant the DNA cloud from the chromosome XII/IV band, the shorter and/or more relaxed the DNA structures it comprises (see Figure 2A, Figure 3). In general, $X$ structures, lariats, D-loop and R-loops were rarely observed in the analyzed samples, possibly because the samples were obtained from stationary-phase cells. However, we detected a few R-loops in $\mathrm{rrm} 3 / \mathrm{rrm} 3$ and pifl/pifl even during stationary-phase growth, but circular DNA and Y-structures were observed in these samples more frequently (Figure 3 ). This result suggests that, in stationary phase, when replication does not disturb transcription, no toxic DNA structures linked to replication stall or replication/transcription collisions are formed.

Circular DNA of different sizes was particularly predominant in the pifl/pifl samples. The Pif1 5'-to3' helicase potentially unwinds G-quadruplexes (G4structures), which are particularly frequent in the rDNA region and in RNA:DNA hybrids [29, 51, 52]. Rrm3 is a 5'-to-3' DNA helicase that promotes replication-fork progression through repetitive sequences [53]. A lack of Rrm3 stimulates HR [20]. A recombination event between different repeat sequences in the rDNA array might lead to the formation of circular DNA forms containing different numbers of rDNA units [13], as observed in the chromosome comet assay. Notably, the circular DNA structures that were detected by our chromosome comet assays in the samples retrieved from PFGE gels are not the mono- and diERCs that characterize, for example, the $\operatorname{sgs} / \mathrm{sgs}_{1}$ mutant [54]. Molecules of this size already run out of the gel after over 20 hours of electrophoresis. Therefore, we do not see circular DNA structures in the sgs 1/sgs 1 sample in our experiments, even though the lack of Sgs1 does lead to an increased rate of mono- and diERCs in the cell. Interestingly, Rad52 which is essential for the formation of mono- and diERCs [55], seems to be less important for the formation of big DNA circles, since such structures were observed quite often in $\mathrm{rad} 52 / \mathrm{rad} 52$ mutants.

An interesting protein identified by ASPIC-MS was $\mathrm{Tfb} 3$, a subunit of the TFIIH transcription factor. This subunit of both RNA polymerase II and RNA polymerase I is also required for nucleotide excision repair $[56,57]$ and was detected in $\mathrm{rad} 52 / \mathrm{rad} 52$ and sgs 1/sgs 1 chromosome XII/IV samples and in the rpa12/ rpa12 DNA cloud sample. The presence of Tfb3 might be associated with increased demand for this protein in the corresponding strains. Rad52 is necessary for functional 
Table 2: Yeast strains used in this study

\begin{tabular}{|c|c|c|}
\hline Strain & Genotype & Notes \\
\hline BY4743 & 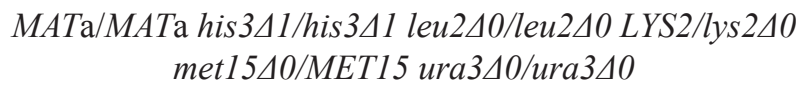 & Open Biosystems \\
\hline fobl/fobl & BY4743 fob1 $:: k a n M X 4 / f o b 1 \Delta:: k a n M X 4$ & Open Biosystems \\
\hline pif1/pif1 & BY4743 pif1 $:: k a n M X 4 / p i f 1 \Delta:: k a n M X 4$ & Open Biosystems \\
\hline $\mathrm{rad} 52 / \mathrm{rad} 52$ & BY4743 rad524::kanMX4/rad524::kanMX4 & Open Biosystems \\
\hline rpa12/rpa12 & BY4743 rpa124::kanMX4/rpa124::kanMX4 & Open Biosystems \\
\hline $\mathrm{rrm} 3 / \mathrm{rrm} 3$ & BY4743 rrm3ム::kanMX4/rrm34::kanMX4 & Open Biosystems \\
\hline $\operatorname{sgs} 1 / \operatorname{sgs} 1$ & BY4743 sgs 14::kanMX4/sgs1 $: \because k a n M X 4$ & Open Biosystems \\
\hline BY4741 & Mat a his3 31 leu $2 \Delta 0$ met $15 \Delta 0$ ura $3 \Delta 0$ & Open Biosystems \\
\hline fobl & BY4741 fob1 $:: k a n M X 4$ & Open Biosystems \\
\hline pif1 & BY4741 pif1 $1:$ kanMX4 & Open Biosystems \\
\hline $\operatorname{rad} 52$ & $\mathrm{BY} 4741 \operatorname{rad} 52 \Delta:: k a n M X 4$ & Open Biosystems \\
\hline rpa12 & BY4741 rpa124::kanMX4 & Open Biosystems \\
\hline rrm3 & BY4741 rrm34::kanMX4 & Open Biosystems \\
\hline $\operatorname{sgs} 1$ & $\mathrm{BY} 4741 \operatorname{sgs} 1 \Delta:: \operatorname{kan} M X 4$ & Open Biosystems \\
\hline KAY757 & 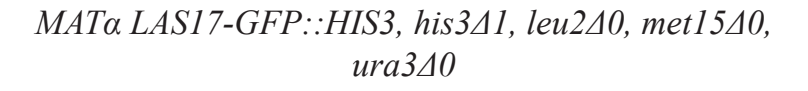 & {$[36]$} \\
\hline RLY1 & MATa ura3-52 his3-4200 leu2-3,112 lys2-801 & {$[73]$} \\
\hline RLY157 & RLY1 las17(bee1)::LEU2 & {$[73]$} \\
\hline
\end{tabular}

HR [58], and Rpa12 is required for the proper assembly of RNA polymerase I [31, 59], whereas Sgs1 is involved in various DNA repair pathways that require the unwinding of double-stranded DNA [60]. The absence of any of these proteins promotes DSBs, which should be repaired. In the rad52/rad52 and sgs1/sgs 1 strains, which lack functional HR, a good alternative is transcription-coupled repair. Using the same repair pathway is the natural choice when damage occurs during faulty transcription in the rpa12/rpa12 strain. Because Tfb3 and most likely the whole TFIIB complex are mobilized to repair DNA damage in the $\mathrm{rad} 52 / \mathrm{rad} 52, \mathrm{sgs} 1 / \mathrm{sgs} 1$ and $\mathrm{rpa} 12 / \mathrm{rpa} 12$ strains, the simultaneous presence of the Yku80 protein in the samples derived from these strains might suggest that Yku80 protein functions in transcription-coupled repair similar to its orthologue, Ku80 in mammalian cells [61]. Interestingly, the $\mathrm{rrm} 3 / \mathrm{rrm} 3$ and pif1/pif1 samples also contained the Yku80 protein, which may suggest an additional role for this protein in these mutants.

The most frequently observed class of DNA was the Y structure, which accumulated in all cloud samples except in those from the rpa12/rpal2 and fob1/ fob1 strains. Y structures are usually associated with transcription and are less frequent in strains that are defective in transcription and in strains that lack proper functioning of the replication barrier. The increased number of $Y$ structures was predictable in samples from the pif1/pif1 strain because the Pif1 helicase unwinds RNA/DNA duplexes [29].

ASPIC-MS analysis of rad52/rad52- and sgs 1/ sgs 1-derived samples also identified Sod1, which exhibits superoxide dismutase activity. However, under increased levels of reactive oxygen species, this protein relocates to the nucleus, where it regulates the expression of oxidative stress-responsive genes by directly binding to their promoters [62]. The rad52/rad52 strain showed elevated levels of reactive oxygen species [25], potentially explaining the presence of Sod1 in this sample.

In addition to proteins whose nucleolar localization was already known, ASPIC-MS enabled the identification of proteins not annotated to the nucleolus. One of these proteins was Las 17, a homolog of human WASP [63, 64], an actin-binding protein present at the actin cortical path that activates the nucleation of actin filaments [65-67]. Our co-localization experiment employing a Las17-GFP fusion protein and the nucleolar marker Nop1-DsRed confirmed the nucleolar localization of Las17, further validating the ASPIC-MS method for the identification of chromatinbound proteins (Figure 4A). Further experiments employing the las17A mutant revealed differences in nucleolar integrity, shape and positioning during cell division compared with WT, suggesting a role for Las 17 
in nucleolar organization and division (Figure 4B, Supplementary Figure 3). This result is also in agreement with the higher nucleolar fragmentation score observed in the las 17 mutant in a genomic screen [68]. Because Las 17 overexpression protects cells against stresses that affect the nucleolus, such as starvation, cell wall stress or oxidative stress [69], we suppose that the involvement of Las 17 in cell growth regulation, extrachromosomal DNA transportation and stress responses is linked to its role in nucleolar organization.

The results presented here demonstrate that the DNA cloud observed in PFGE analysis represents an altered form of chromosome XII. Differences in the cloud shape may result from the presence of special DNA structures and DNA-interacting proteins involved in the creation or maintenance of such structures. The structures and proteins detected in the cloud suggest that the cloud represents chromosome XII and that its parts that form the nucleolus are still uncondensed and are metabolically active. This conclusion is supported by the fact that, in budding yeast mitotic chromosomes, segregation is precisely ordered, and the rDNA-bearing chromosomal region segregates as the last step [70]. rDNA region condensation and resolution occurs in anaphase, after the successful separation of the rest of the yeast chromatids [71, 72]. We also demonstrated that the shape of the DNA cloud can be linked to aberrations in nucleolus morphology and functioning. Moreover, we developed a method that permits the identification of DNA-bound proteins even from a very small amount of available material, ASPIC-MS. Using this method, we identified a new role of Las 17 in nucleolus organization and division and obtained valuable information about proteins adhering to PFGEseparated chromosomes.

\section{MATERIALS AND METHODS}

\section{Yeast strains, plasmids, materials, and growth conditions}

Most $S$. cerevisiae strains used in this study were

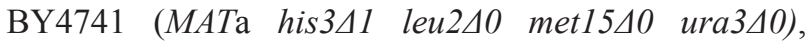

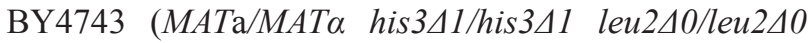

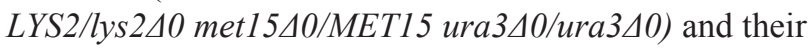
derivatives carrying whole-gene deletions (see Table 2). Deletion strains were created as part of the Saccharomyces Genome Deletion Project (http://www-sequence.stanford. edu/group/yeast_deletion_project/) and were obtained from Open Biosystems (Huntsville, USA). The KAY757 (LAS17-GFP), RLY1 and RLY157 (las174) strains were prepared as described previously $[36,73]$.

The plasmid pGAL-I-PpoI was kindly provided by Volker M. Vogt [28], and the plasmid pWJ1322 bearing a gene encoding Nop1-DsRed fusion was provided by Michael Lisby [22].
Yeast strains were grown at $28^{\circ} \mathrm{C}$ in YPD medium containing $1 \%$ yeast extract (Difco, Mt. Pritchard, NSW, Australia), 2\% peptone (Difco), 2\% glucose (POCh, Gliwice, Poland) or in synthetic complete medium (SC) containing $0.67 \%$ yeast nitrogen base (Difco), and 2\% glucose, supplemented with necessary amino acids, uracil and adenine (Formedium, Hunstanton, UK). Liquid cultures were grown at 200 RPM agitation (New Brunswick Scientific, Edison, NJ, USA). The media and buffers were sterilized in an EnbioJet microwave autoclave (Enbio Technology, Kosakowa, Poland).

\section{Cloud assay}

\section{PFGE plug preparation}

Unless stated otherwise, $S$. cerevisiae strains were grown for 3-4 days on solid YPD medium. Next, cells were scraped out and washed with water, and samples of $1.6 \times 10^{8}$ of cells suspended in $1 \mathrm{ml}$ of water were taken for analysis. For experiments with logarithmically grown cells, yeast was cultured in liquid medium to a density of approximately $1 \times 10^{7}$ to $2 \times 10^{7}$ cells per ml. To arrest cells in G2/M phase, nocodazole (USBiological, Salem, MA, USA) was added to a final concentration of $15 \mu \mathrm{g}$ per $\mathrm{ml}$. After three hours of incubation at $28^{\circ} \mathrm{C}$, with shaking, the cells were spun down, washed with water, and killed by incubation with $\mathrm{NaN}_{3}$ (Sigma-Aldrich, St. Louis, MO, USA) at a final concentration of $20 \mathrm{mM}$ for $5 \mathrm{~min}$. The cells were then washed in $1 \mathrm{ml}$ of $50 \mathrm{mM}$ EDTA, $\mathrm{pH}$ 8.0, spun down (1 min, 3,000 rpm in microcentrifuge) and resuspended in $1 \mathrm{M}$ sorbitol (Merck, Darmstadt, Germany), 0.1 M EDTA (Merck), pH 8.0, supplemented with $50 \mu \mathrm{l}$ of $2.5 \mathrm{mg} / \mathrm{ml}$ Zymolyase 100T (BioShop, Burlington, ON, Canada) in $50 \mathrm{mM}$ EDTA, pH 8.0. Next, $110 \mu$ of $1.2 \%$ InCern LMP agarose (Lonza, Basel, Switzerland) in $0.1 \mathrm{mM}$ EDTA, $\mathrm{pH} 8$ (melted at $85^{\circ} \mathrm{C}$ and cooled to $55^{\circ} \mathrm{C}$ ), was added to the cell suspension and mixed gently. The suspension was then placed in a 2-ml syringe (Becton-Dickinson, Franklin Lakes, NJ, USA) to solidify. The barrels of agarose-embedded cells were cut into 8 equal pieces (ca. $2 \times 10^{7}$ cells per plug). The plugs were placed in 2-ml Eppendorf tubes and incubated in $1 \mathrm{ml}$ of Zymolyase solution (1 M Sorbitol, $20 \mathrm{mM}$ EDTA, pH 8.0, 10 mM Tris-HCl, pH 8.0, 1 mg/ml Zymolyase $100 \mathrm{~T})$ at $37^{\circ} \mathrm{C}$ with gentle rotation $(4 \mathrm{rpm})$ in a rotator SB3 (Bibby Sterlin LTD, Stone, UK) overnight. The Zymolyase solution was then removed, and the plugs were rinsed twice with $2 \mathrm{ml}$ of $50 \mathrm{mM}$ EDTA, $\mathrm{pH}$ 8.0, and incubated in $1 \mathrm{ml}$ of freshly prepared proteinase solution containing $50 \mathrm{mM}$ EDTA, $\mathrm{pH} 8.0,10 \mathrm{mM}$ Tris- $\mathrm{HCl}, \mathrm{pH}$ $8.0,1 \% \mathrm{~N}$-lauroylsarcosine, $0.2 \%$ sodium deoxycholate, $1 \mathrm{mg}$ of proteinase K (Sigma-Aldrich), and $100 \mu \mathrm{g}$ of RNase A (Sigma-Aldrich) and incubated overnight at $37^{\circ} \mathrm{C}$ with gentle rotation $(4 \mathrm{rpm})$. Then, the plugs were rinsed twice with $2 \mathrm{ml}$ of $50 \mathrm{mM}$ EDTA and incubated in $2 \mathrm{ml}$ of $1 \mathrm{x} \mathrm{TE}$ at $37^{\circ} \mathrm{C}$ for 1 hour with rotation at $4 \mathrm{rpm}$. 
In some experiments, agarose-embedded genomic DNA was digested with restriction enzymes prior to electrophoresis. For these experiments, DNA plugs were equilibrated in the appropriate buffer for the enzyme for 1 hour. Then, the buffer was replaced with fresh buffer, and the enzymes were added. BamHI and EcoRI (Thermo Fisher Scientific), RecBCD nuclease (New England Biolabs, UK) and I-PpoI (Promega, Madison, WI, USA) were used.

\section{Pulsed-field gel electrophoresis (PFGE)}

PFGE was performed as previously described [25] with modifications enabling greater separation of highmolecular-weight DNA molecules, such as chromosome XII, from the rDNA cloud. Plugs were placed in the wells of a $0.8 \%$ agarose gel (D5 agarose (Conda, Torrejon de Ardoz, Madrid, Spain) in 1x TAE) and sealed with the same agarose. Until stated otherwise, electrophoresis was performed for 24 hours in $1 \mathrm{x}$ TAE buffer at $6 \mathrm{~V} / \mathrm{cm}, 12^{\circ} \mathrm{C}$, ramping 0.8 , angle $120^{\circ}$, switch time $60-85 \mathrm{~s}$, using a CHEF Mapper ${ }^{\circledR}$ XA Pulsed Field Electrophoresis System (BioRad, Hercules, CA, USA). After electrophoresis, DNA was stained with $0.5 \mu \mathrm{g} / \mathrm{ml}$ ethidium bromide (Sigma-Aldrich) for $30 \mathrm{~min}$, washed twice with water for $15 \mathrm{~min}$, and photographed using a 302-nm UV light for DNA visualization with a charge-coupled device camera (Fluorchem Q Multi Image III, Alpha Innotech, San Leandro, CA, USA).

\section{Southern blot}

To detect chromosome XII DNA, Southern blot analysis was performed. PFGE-separated genomic DNA was capillary transferred to nylon membranes (SigmaAldrich). Hybridization was performed in a minihybridization oven OV2 (Biometra, Göttingen, Germany) overnight at $65^{\circ} \mathrm{C}$. The hybridization solution contained $250 \mathrm{mM}$ NaPi, pH 6.5, 1 mM EDTA, 1\% BSA (Biomol $\mathrm{GmbH}$, Hamburg, Germany), 7\% sodium dodecyl sulfate (Biomol, Enzo Life Sciences, Farmingdale, NY, USA) and radiolabeled probe. Three hybridization probes were prepared by PCR amplification using total DNA from the BY4741 strain as a template: $R D N 25-1$ probe, $430 \mathrm{bp}$ DNA fragment of the RDNA25-1 gene using RDN25A. up 5'-GATGGATTTGAGTAAGAGCA-3' and RDN25A. lw 5'-GGTGTCTGATGAGCGTGTAT-3' primers; LEU3 probe, 765 bp fragment of LEU3 gene using LEU3s. up 5'-TCGCCTGTGTGGAATGT-3' and LEU3s.lw 5'-CGGGTTCGTCCTTATCT-3' primers and POM33 probe, $637 \mathrm{bp}$ fragment of $P O M 33$ gene using POM33s.up 5'-ATCAAGACCCGCTAATAACC-3' and POM33s.lw 5'-AAAGATGGCGTACACAACAA-3' primers. Probes were labeled by random priming using a DecaLabel DNA Labeling Kit (Thermo Fisher Scientific, Poland) and $\left[\alpha^{32} \mathrm{P}\right]$ ATP $\left(3,000 \mathrm{Ci} \mathrm{mmol}^{-1}\right.$; Hartmann Analytic $\mathrm{GmbH}$, Braunschweig, Germany) according to the supplier's guidance. After hybridization, the filters were washed with $2 \mathrm{xSC}, 0.1 \%$ SDS solution once at room temperature and again at $50^{\circ} \mathrm{C}$. Radioactive signals were registered using a Storage Phosphor Screen (FujiFilm, BAS gauge 2040) and visualized using a FujiFilm FLA-7000 scanner.

To detect chromosome IV DNA, Southern blot analysis was performed as described above. The hybridization probes used in the experiment were labeled by random priming of two different DNA fragments obtained from PCR reactions using BY4741 DNA as the template. The PHM6 probe was an 837-bp DNA fragment of the PHM6 gene amplified using the PHM6. up 5'-ATTTGGATGTTCTGCCCTAT-3' and PHM6. lw 5'-TTTTCTTGACTGCGGTGTTC-3' primers. The $\mathrm{HO}$ probe was a 705-bp DNA fragment of the $\mathrm{HO}$ gene purified from the agarose gel after BamHI digestion of a 1.8-kb PCR product, amplified using the HO-ATG.up 5'-A TGTTTAAACATGCTTTCTGAAAACACGGACT-3' and HO-STOP.lw 5'-AAGCGGCCGCTTTACTTTTATTACA TACAACTTTTTAAAC-3' primers.

\section{Detection of rDNA repeat numbers}

Total yeast DNA was isolated as described previously [23]. Next, $10 \mu \mathrm{g}$ of total DNA was digested with BamHI, an enzyme that does not cut within rDNA arrays. Then, PFGE was performed, followed by capillary transfer onto nylon membranes (Sigma-Aldrich) and Southern hybridization with the $\left[\alpha^{32} \mathrm{P}\right]$ ATP-labeled RDN25-1 probe. Radioactive signals were registered using a FujiFilm FLA-7000 scanner.

\section{Chromosome comet assay}

DNA strand structures present in chromosome XII or DNA cloud bands after PFGE were visualized by a simplified procedure of a chromosome comet assay [27]. Agarose bands excised from PFGE gels were placed distally on poly-1-lysine coated microscopic slides (CometSlide, Trevigen, Gaithersburg, MD, USA) and covered with $40 \mu \mathrm{l}$ of $0.6 \%$ New Sieve Low Melting Point agarose (Conda). After agarose solidification, the slide was placed in $30 \mathrm{mM} \mathrm{NaOH}$ (POCh), $1 \mathrm{mM}$ EDTA, $\mathrm{pH}>12$, for $10 \mathrm{~min}$ to denature the chromosomal DNA. Electrophoresis was performed under denaturing conditions in $30 \mathrm{mM} \mathrm{NaOH}, 1 \mathrm{mM}$ EDTA, $\mathrm{pH}>12$, for 15-20 min and at 0.1 A for $15 \mathrm{~min}$. After electrophoresis, agarose neutralization and DNA precipitation were performed by soaking 3 times for $30 \mathrm{~min}$ in N/P solution: $50 \%$ ethanol (Polmos, Warszawa, Poland), $1 \mathrm{mg} / \mathrm{ml}$ spermidine (Sigma-Aldrich), and $20 \mathrm{mM}$ Tris $\mathrm{HCl}, \mathrm{pH}$ 7.4. Chromosomal DNA was stained with the fluorescent dye YOYO-1 (Thermo Fisher Scientific Inc., Poland) by spotting the staining solution (0.25 mM YOYO-1, 2.5\% DMSO (Sigma-Aldrich), 0.5\% sucrose (Schwarz/Mann, Orangeburg, NY, USA) on the slide. DNA structures were examined using an Axio Imager M2 fluorescence microscope (Zeiss, Oberkochen, Germany) equipped with a $38 \mathrm{HE}$ filter set. Images were collected, archived and processed using Axio Vision 4.8. 


\section{Identification of agarose squeezed proteins that interact with chromatin by mass spectrometry (ASPIC-MS)}

\section{Isolation of proteins from agarose}

Pieces of agarose containing the DNA of interest were excised from the PFGE gel and incubated at $99^{\circ} \mathrm{C}$ for $5 \mathrm{~min}$ to dissolve the agarose. The agarose was depolymerized by incubation with $2 \mathrm{U}$ of $\beta$-agarase (New England Biolabs, UK) and $11 \mu \mathrm{l}$ of supplied 10x buffer per $100 \mathrm{mg}$ of excised agarose for $2-4$ hours in $42-45^{\circ} \mathrm{C}$. Then, $\mathrm{MgCl}_{2}$ at a final concentration of $2 \mathrm{mM}$ and 125 $\mathrm{U}(0.5 \mu \mathrm{l})$ of Viscolase (A\&A Biotechnology, Gdansk, Poland) per $100 \mathrm{mg}$ of the initial amount of agarose were added and incubated for 2 hours at $42^{\circ} \mathrm{C}$ to degrade the DNA. The resultant samples were subjected to mass spectrometry analysis.

\section{Mass spectrometry}

The peptide mixtures were analyzed by liquid chromatography coupled to tandem mass spectrometry LC-(MS-MS/MS) using a Nano-Acquity (Waters, Milford, Massachusetts, USA) LC system and Orbitrap Velos mass spectrometer (Thermo Electron Corp., San Jose, $\mathrm{CA}$ ). Prior to analysis, the proteins were subjected to an in-solution digestion procedure in which proteins were reduced with $50 \mathrm{mM} \mathrm{TCEP} \mathrm{(for} 30 \mathrm{~min}$ at $60^{\circ} \mathrm{C}$ ), alkylated with $200 \mathrm{mM}$ MMTA (30 min at room temperature) and digested overnight with trypsin (sequencing Grade Modified Trypsin - Promega V5111). The peptide mixture was applied to an RP-18 precolumn (nanoACQUITY Symmetry ${ }^{\circledR}$ C18 - Waters 186003514) using water containing $0.1 \%$ TFA as a mobile phase and transferred to a nano-HPLC RP-18 column (nanoACQUITY BEH C18 Waters 186003545) using an acetonitrile gradient (0-35\% AcN in $180 \mathrm{~min}$ ) in the presence of $0.05 \%$ formic acid at a flow rate of $250 \mathrm{nl} / \mathrm{min}$. The column outlet was directly coupled to the ion source of the spectrometer working in the regime of data dependent MS to MS/MS switch. A blank run preceded each analysis to ensure a lack of cross contamination from previous samples.

Raw data were processed with a Mascot Distiller followed by a Mascot Search (Matrix Science, London, UK, on-site license) against SGD and the UniProt database. The search parameters for precursor and product ion mass tolerances were $20 \mathrm{ppm}$ and $0.1 \mathrm{Da}$, respectively; enzyme specificity: trypsin; missed cleavage sites allowed: 0 ; fixed modification of cysteine by methylthio; variable methionine oxidation. Peptides with Mascot Scores exceeding the threshold value of $<5 \%$ calculated by the Mascot procedure were considered positively identified.

\section{Fluorescence microscopy}

A co-localization study was performed using exponentially growing KAY575 cells transformed with pWJ1322 on SC-URA media. Cells were examined using an Axio Imager M2 fluorescence microscope (Zeiss) equipped with 38HE and 20HE filter sets for Las 17-GFP and Nop1-DsRed, respectively and was documented using Axio Vision 4.8.

For the nucleolus morphology assay, RLY1 (wild type, WT) or RLY157 (las174) cells carrying pWJ1322 (Nop1-DsRed) were grown on SC-URA media, washed twice in PBS and viewed with an Eclipse (Nikon, Amsterdam, Netherlands) fluorescence microscope equipped with a Hamamatsu ORCA 100 camera. Images were collected using Lucia G software. The morphology of the nucleolus was analyzed in at least 350 cells.

To analyze nucleolus morphology during division, yeast transformants grown on selective media (SC-ura) were cultivated in YPD to the exponential growth phase, and then $7.5 \mu \mathrm{g} / \mathrm{ml}$ was added to the WT and las 174 strains. YPD is superior to synthetic media for nocodazole synchronization. After further cultivation for 2 hours, cells were washed and then suspended in fresh medium. At 30, 60, 90 and 120 min after the removal of nocodazole, cells were observed, and images were collected as described above.

\section{ACKNOWLEDGMENTS}

We thank Dr. Volker M. Vogt and Dr. Michael Lisby for providing the plasmids and Dr. Maciej Wnuk for teaching us how to perform the chromosome comet assay.

\section{CONFLICTS OF INTEREST}

Authors declare no conflicts of interest.

\section{GRANT SUPPORT}

This work was supported by the Polish National Science Center grant 2011/03/B/NZ2/00293 to AS.

\section{REFERENCES}

1. Petes TD. Yeast ribosomal DNA genes are located on chromosome XII. Proc Natl Acad Sci U S A. 1979; 76:410-414.

2. Warner JR. Synthesis of ribosomes in Saccharomyces cerevisiae. Microbiol Rev. 1989; 53:256-271.

3. Miyazaki T, Kobayashi T. Visualization of the dynamic behavior of ribosomal RNA gene repeats in living yeast cells. Genes Cells Devoted Mol Cell Mech. 2011; 16:491-502.

4. Nogi Y, Vu L, Nomura M. An approach for isolation of mutants defective in $35 \mathrm{~S}$ ribosomal RNA synthesis in Saccharomyces cerevisiae. Proc Natl Acad Sci U S A. 1991; 88:7026-7030.

5. Tekamp PA, Garcea RL, Rutter WJ. Transcription and in vitro processing of yeast $5 \mathrm{~S}$ rRNA. J Biol Chem. 1980; 255:9501-9506. 
6. Warner JR. The economics of ribosome biosynthesis in yeast. Trends Biochem Sci. 1999; 24:437-440.

7. Dammann R, Lucchini R, Koller T, Sogo JM. Chromatin structures and transcription of rDNA in yeast Saccharomyces cerevisiae. Nucleic Acids Res. 1993; 21:2331-2338.

8. Meier A, Thoma F. RNA polymerase I transcription factors in active yeast rRNA gene promoters enhance UV damage formation and inhibit repair. Mol Cell Biol. 2005; 25:1586-1595.

9. Meier A, Livingstone-Zatchej M, Thoma F. Repair of active and silenced rDNA in yeast: the contributions of photolyase and transcription-coupled nucleotide excision repair. J Biol Chem. 2002; 277:11845-11852.

10. Hamperl S, Cimprich KA. The contribution of co-transcriptional RNA:DNA hybrid structures to DNA damage and genome instability. DNA Repair. 2014;19:84-94.

11. Salvi JS, Chan JNY, Szafranski K, Liu TT, Wu JD, Olsen JB, Khanam N, Poon BPK, Emili A, Mekhail K. Roles for $\mathrm{Pbp} 1$ and caloric restriction in genome and lifespan maintenance via suppression of RNA-DNA hybrids. Dev Cell. 2014; 30:177-191.

12. Stuckey R, García-Rodríguez N, Aguilera A, Wellinger RE. Role for RNA:DNA hybrids in origin-independent replication priming in a eukaryotic system. Proc Natl Acad Sci U S A. 2015; 112:5779-5784.

13. Kobayashi T. Strategies to maintain the stability of the ribosomal RNA gene repeats--collaboration of recombination, cohesion, and condensation. Genes Genet Syst. 2006; 81:155-161.

14. Kobayashi T. Ribosomal RNA gene repeats, their stability and cellular senescence. Proc Jpn Acad Ser B Phys Biol Sci. 2014; 90:119-129.

15. Tsang CK, Zheng XFS. Opposing role of condensin and radiation-sensitive gene RAD52 in ribosomal DNA stability regulation. J Biol Chem. 2009; 284:21908-21919.

16. Rustchenko EP, Curran TM, Sherman F. Variations in the number of ribosomal DNA units in morphological mutants and normal strains of Candida albicans and in normal strains of Saccharomyces cerevisiae. J Bacteriol. 1993; 175:7189-7199.

17. Ganley ARD, Kobayashi T. Monitoring the rate and dynamics of concerted evolution in the ribosomal DNA repeats of Saccharomyces cerevisiae using experimental evolution. Mol Biol Evol. 2011; 28:2883-2891.

18. Ide S, Miyazaki T, Maki H, Kobayashi T. Abundance of ribosomal RNA gene copies maintains genome integrity. Science. 2010; 327:693-696.

19. Deregowska A, Adamczyk J, Kwiatkowska A, Gurgul A, Skoneczny M, Skoneczna A, Szmatola T, Jasielczuk I, Magda M, Rawska E, Pabian S, Panek A, Kaplan $\mathrm{J}$, et al. Shifts in rDNA levels act as a genome buffer promoting chromosome homeostasis. Cell Cycle. 2015; $14: 3475-3487$.

20. Keil RL, McWilliams AD. A gene with specific and global effects on recombination of sequences from tandemly repeated genes in Saccharomyces cerevisiae. Genetics. $1993 ; 135: 711-718$.

21. Weitao T, Budd M, Campbell JL. Evidence that yeast SGS1, DNA2, SRS2, and FOB1 interact to maintain rDNA stability. Mutat Res. 2003; 532:57-72.

22. Torres-Rosell J, Sunjevaric I, De Piccoli G, Sacher M, Eckert-Boulet N, Reid R, Jentsch S, Rothstein R, Aragón L, Lisby M. The Smc5-Smc6 complex and SUMO modification of Rad52 regulates recombinational repair at the ribosomal gene locus. Nat Cell Biol. 2007; 9:923-931.

23. Alabrudzinska M, Skoneczny M, Skoneczna A. Diploidspecific genome stability genes of S. cerevisiae: genomic screen reveals haploidization as an escape from persisting DNA rearrangement stress. PLoS ONE. 2011; 6:e21124.

24. Deregowska A, Skoneczny M, Adamczyk J, Kwiatkowska A, Rawska E, Skoneczna A, Lewinska A, Wnuk M. Genome-wide array-CGH analysis reveals YRF1 gene copy number variation that modulates genetic stability in distillery yeasts. Oncotarget. 2015; 6:30650-3063. doi: 10.18632/oncotarget.5594.

25. Krol K, Brozda I, Skoneczny M, Bretner M, Skoneczna A. A genomic screen revealing the importance of vesicular trafficking pathways in genome maintenance and protection against genotoxic stress in diploid Saccharomyces cerevisiae cells. PloS One. 2015; 10:e0120702.

26. Blake D, Luke B, Kanellis P, Jorgensen P, Goh T, Penfold S, Breitkreutz B-J, Durocher D, Peter M, Tyers M. The F-box protein Dia2 overcomes replication impedance to promote genome stability in Saccharomyces cerevisiae. Genetics. 2006; 174:1709-1727.

27. Lewinska A, Miedziak B, Wnuk M. Assessment of yeast chromosome XII instability: single chromosome comet assay. Fungal Genet Biol FG B. 2014; 63:9-16.

28. Muscarella DE, Vogt VM. A mobile group I intron from Physarum polycephalum can insert itself and induce point mutations in the nuclear ribosomal DNA of Saccharomyces cerevisiae. Mol Cell Biol. 1993; 13:1023-1033.

29. Boulé J-B, Zakian VA. The yeast Piflp DNA helicase preferentially unwinds RNA DNA substrates. Nucleic Acids Res. 2007; 35:5809-5818.

30. Sinclair DA, Guarente L. Extrachromosomal rDNA circles--a cause of aging in yeast. Cell. 1997; 91:1033-1042.

31. Nogi Y, Yano R, Dodd J, Carles C, Nomura M. Gene RRN4 in Saccharomyces cerevisiae encodes the A12.2 subunit of RNA polymerase I and is essential only at high temperatures. Mol Cell Biol. 1993; 13:114-122.

32. Kobayashi T, Horiuchi T. A yeast gene product, Fob1 protein, required for both replication fork blocking and recombinational hotspot activities. Genes Cells Devoted Mol Cell Mech. 1996; 1:465-474. 
33. Adamczyk J, Deregowska A, Panek A, Golec E, Lewinska A, Wnuk M. Affected chromosome homeostasis and genomic instability of clonal yeast cultures. Curr Genet. 2016; 62:405-418.

34. Lewinska A, Miedziak B, Kulak K, Molon M, Wnuk M. Links between nucleolar activity, rDNA stability, aneuploidy and chronological aging in the yeast Saccharomyces cerevisiae. Biogerontology. 2014; 15: 289-316.

35. Li H, Pagé N, Bussey H. Actin patch assembly proteins Las $17 p$ and Sla1p restrict cell wall growth to daughter cells and interact with cis-Golgi protein Kre6p. Yeast Chichester Engl. 2002; 19:1097-1112.

36. Rooij IIS -d., Allwood EG, Aghamohammadzadeh S, Hettema EH, Goldberg MW, Ayscough KR. A role for the dynamin-like protein $\mathrm{Vps} 1$ during endocytosis in yeast. J Cell Sci. 2010; 123:3496-3506.

37. Kobayashi T, Heck DJ, Nomura M, Horiuchi T. Expansion and contraction of ribosomal DNA repeats in Saccharomyces cerevisiae: requirement of replication fork blocking (Fob1) protein and the role of RNA polymerase I. Genes Dev. 1998; 12:3821-3830.

38. Kobayashi T, Horiuchi T, Tongaonkar P, Vu L, Nomura M. SIR2 regulates recombination between different rDNA repeats, but not recombination within individual rRNA genes in yeast. Cell. 2004; 117: 441-453.

39. Kaliraman V, Brill SJ. Role of SGS1 and SLX4 in maintaining rDNA structure in Saccharomyces cerevisiae. Curr Genet. 2002; 41: 389-400.

40. Westmoreland J, Ma W, Yan Y, Van Hulle K, Malkova A, Resnick MA. RAD50 is required for efficient initiation of resection and recombinational repair at random, gammainduced double-strand break ends. PLoS Genet. 2009; 5: e1000656.

41. Arnold DA, Kowalczykowski SC. RecBCD Helicase/ Nuclease. In: John Wiley \& Sons, Ltd, editor. Encyclopedia of Life Sciences [Internet]. Chichester, UK: John Wiley \& Sons, Ltd; 2001 [cited 2016 Apr 12]. Available from: http:// doi.wiley.com/10.1038/npg.els.0000586.

42. Horiuchi T, Fujimura Y, Nishitani H, Kobayashi T, Hidaka M. The DNA replication fork blocked at the Ter site may be an entrance for the RecBCD enzyme into duplex DNA. J Bacteriol. 1994; 176:4656-4663.

43. Courcelle J, Wendel BM, Livingstone DD, Courcelle CT. RecBCD is required to complete chromosomal replication: Implications for double-strand break frequencies and repair mechanisms. DNA Repair. 2015; 32:86-95.

44. Taylor AF, Smith GR. Action of RecBCD enzyme on cruciform DNA. J Mol Biol. 1990; 211:117-134.

45. Chayot R, Montagne B, Mazel D, Ricchetti M. An endjoining repair mechanism in Escherichia coli. Proc Natl Acad Sci U S A. 2010; 107:2141-2146.

46. Palmbos PL, Daley JM, Wilson TE. Mutations of the Yku80 C terminus and Xrs2 FHA domain specifically block yeast nonhomologous end joining. Mol Cell Biol. 2005; 25:10782-10790.

47. Ciosk R, Shirayama M, Shevchenko A, Tanaka T, Toth A, Shevchenko A, Nasmyth K. Cohesin's binding to chromosomes depends on a separate complex consisting of Scc2 and Scc4 proteins. Mol Cell. 2000; 5:243-254.

48. Ström L, Lindroos HB, Shirahige K, Sjögren C. Postreplicative recruitment of cohesin to double-strand breaks is required for DNA repair. Mol Cell. 2004; 16:1003-1015.

49. Dion V, Kalck V, Seeber A, Schleker T, Gasser SM. Cohesin and the nucleolus constrain the mobility of spontaneous repair foci. EMBO Rep. 2013; 14:984-991.

50. Cortés-Ledesma F, Tous C, Aguilera A. Different genetic requirements for repair of replication-born doublestrand breaks by sister-chromatid recombination and break-induced replication. Nucleic Acids Res. 2007; 35:6560-6570.

51. Chung W-H. To peep into Pif1 helicase: multifaceted all the way from genome stability to repair-associated DNA synthesis. J Microbiol Seoul Korea. 2014; 52:89-98.

52. Hershman SG, Chen Q, Lee JY, Kozak ML, Yue P, Wang L-S, Johnson FB. Genomic distribution and functional analyses of potential G-quadruplex-forming sequences in Saccharomyces cerevisiae. Nucleic Acids Res. 2008; 36:144-156.

53. Ivessa AS, Zhou J-Q, Schulz VP, Monson EK, Zakian VA. Saccharomyces Rrm3p, a 5' to 3' DNA helicase that promotes replication fork progression through telomeric and subtelomeric DNA. Genes Dev. 2002; 16:1383-1396.

54. Zadrag-Tecza R, Skoneczna A. Reproductive potential and instability of the rDNA region of the Saccharomyces cerevisiae yeast: Common or separate mechanisms of regulation? Exp Gerontol. 2016; 84:29-39.

55. Park PU, Defossez PA, Guarente L. Effects of mutations in DNA repair genes on formation of ribosomal DNA circles and life span in Saccharomyces cerevisiae. Mol Cell Biol. 1999; 19:3848-3856.

56. Iben S, Tschochner H, Bier M, Hoogstraten D, Hozák P, Egly JM, Grummt I. TFIIH plays an essential role in RNA polymerase I transcription. Cell. 2002; 109:297-306.

57. Feaver WJ, Huang W, Gileadi O, Myers L, Gustafsson CM, Kornberg RD, Friedberg EC. Subunit interactions in yeast transcription/repair factor TFIIH. Requirement for Tfb3 subunit in nucleotide excision repair. J Biol Chem. 2000; 275:5941-5946.

58. Mortensen UH, Lisby M, Rothstein R. Rad52. Curr Biol. 2009; 19:R676-R677.

59. Van Mullem V, Landrieux E, Vandenhaute J, Thuriaux P. Rpa12p, a conserved RNA polymerase I subunit with two functional domains. Mol Microbiol. 2002; 43:1105-1113.

60. Ashton TM, Hickson ID. Yeast as a model system to study RecQ helicase function. DNA Repair. 2010; 9:303-314. 
61. Hannan RD, Cavanaugh A, Hempel WM, Moss T, Rothblum L. Identification of a mammalian RNA polymerase I holoenzyme containing components of the DNA repair/replication system. Nucleic Acids Res. 1999; 27:3720-3727.

62. Tsang CK, Liu Y, Thomas J, Zhang Y, Zheng XFS. Superoxide dismutase 1 acts as a nuclear transcription factor to regulate oxidative stress resistance. Nat Commun. 2014; 5:3446.

63. Naqvi SN, Zahn R, Mitchell DA, Stevenson BJ, Munn AL. The WASp homologue Las17p functions with the WIP homologue End5p/verprolin and is essential for endocytosis in yeast. Curr Biol CB. 1998; 8:959-962.

64. Madania A, Dumoulin P, Grava S, Kitamoto H, SchärerBrodbeck C, Soulard A, Moreau V, Winsor B. The Saccharomyces cerevisiae homologue of human WiskottAldrich syndrome protein Las 17p interacts with the Arp2/3 complex. Mol Biol Cell. 1999; 10:3521-3538.

65. Rodal AA, Manning AL, Goode BL, Drubin DG. Negative regulation of yeast WASp by two $\mathrm{SH} 3$ domain-containing proteins. Curr Biol CB. 2003; 13:1000-1008.

66. Costa R, Warren DT, Ayscough KR. Lsb5p interacts with actin regulators Sla1p and Las17p, ubiquitin and Arf3p to couple actin dynamics to membrane trafficking processes. Biochem J. 2005; 387:649-658.
67. Kaminska J, Spiess M, Stawiecka-Mirota M, Monkaityte R, Haguenauer-Tsapis R, Urban-Grimal D, Winsor B, Zoladek T. Yeast Rsp5 ubiquitin ligase affects the actin cytoskeleton in vivo and in vitro. Eur J Cell Biol. 2011; 90:1016-1028.

68. Neumüller RA, Gross T, Samsonova AA, Vinayagam A, Buckner M, Founk K, Hu Y, Sharifpoor S, Rosebrock AP, Andrews B, Winston F, Perrimon N. Conserved regulators of nucleolar size revealed by global phenotypic analyses. Sci Signal. 2013; 6:ra70.

69. Mizoguchi H, Hara S. Effect of overexpression of LAS17 on stress tolerance and the stability of extrachromosomal DNA in Saccharomyces cerevisiae. J Biosci Bioeng. 2001; 91:33-39.

70. Hernandez-Verdun D. Nucleolus in the spotlight. Cell Cycle. 2005; 4:106-108.

71. Torres-Rosell J, Machín F, Jarmuz A, Aragón L. Nucleolar segregation lags behind the rest of the genome and requires Cdc14p activation by the FEAR network. Cell Cycle. 2004; 3:496-502.

72. Sullivan M, Higuchi T, Katis VL, Uhlmann F. Cdc14 phosphatase induces rDNA condensation and resolves cohesin-independent cohesion during budding yeast anaphase. Cell; 117:471-482.

73. Li R. Bee1, a yeast protein with homology to WiscottAldrich syndrome protein, is critical for the assembly of cortical actin cytoskeleton. J Cell Biol. 1997; 136:649-658. 